\title{
Ethos discursivo e sentidos sobre trabalho no samba
}

\author{
Discursive ethos and senses about working in the samba
}

\author{
Marília Giselda RODRIGUES* \\ Pontifícia Universidade Católica de São Paulo (PUC-SP/CNPq) \\ Maria Cecília Pérez SOUZA-E-SILVA** \\ Pontifícia Universidade Católica de São Paulo (PUC-SP/CNPq)
}

\begin{abstract}
RESUMO: A proposta deste artigo é indagar quais sentidos sobre trabalho e trabalhador a música popular brasileira, mais precisamente o samba, faz circular. Analisamos o ethos discursivo (MAINGUENEAU, 1997, 2005, 2008a) em letras de canções compostas em três momentos diferentes da história do país, em que a temática do trabalho está presente: "O bonde de São Januário", de 1940, de Ataulfo Alves e Wilson Batista, e "Eu trabalhei”, de 1941, gravada por Orlando Silva, produzidas sob a censura imposta pelo Estado Novo de Vargas; "Cotidiano", de Chico Buarque de Holanda, sob a censura do regime militar nos anos 1970; e "Trabalhador", de Seu Jorge, de 2007.
\end{abstract}

PALAVRAS-CHAVE: Linguagem e trabalho. Discurso literomusical. Samba. Ethos discursivo.

ABSTRACT: The proposal of this paper is to investigate which senses on work and worker moves the popular brazilian music, samba to be more precise. We analyze the discursive ethos (MAINGUENEAU, 2008a) in lyrics composed in three different moments in the history of the country, that have the work as subject-matter: " O bonde de São Januário", 1940, composed by Ataulfo Alves and Wilson Batista, and "Eu trabalhei", 1941, registered by Orlando Silva, produced under the censorship imposed by the Estado Novo of Vargas; "Cotidiano", from Chico Buarque de Holanda, wrote in the 1970s under the military regime's censorship; and "Trabalhador", by Seu Jorge, from 2007.

KEYWORDS: Language and work. Literary-musical discourse. Samba. Discursive ethos.

\footnotetext{
* Doutoranda e bolsista do CNPq no Programa de Estudos Pós-Graduados em Linguística Aplicada e Estudos da Linguagem (LAEL), Pontifícia Universidade Católica de São Paulo (PUC-SP). Professora da Universidade de Franca (UNIFRAN). Pesquisadora do Grupo de Estudos do Discurso - GEDI (CNPq) do Centro Universitário de Franca (UNI-FACEF). São Paulo - SP - Brasil. E-mail: mariliagiselda@uol.com.br.

** Doutorado e Mestrado em Linguística Aplicada e Estudos da Linguagem, Pós-doutorado na Université Sorbonne Nouvelle - Paris III. Bolsista Produtividade em Pesquisa do CNPq - nível 1. Professora titular da Pontifícia Universidade Católica de São Paulo (PUC-SP), Programa de Pós-Graduação em Linguística Aplicada e Estudos da Linguagem (LAEL). Líder do grupo Atelier Linguagem e Trabalho (CNPq). Participante do GT da Anpoll Linguagem, Enunciação e Trabalho. Desenvolve pesquisa vinculada ao Departament d'Ergologie - Analyse Pluridisciplinaire des Situations de Travail (APST), da Université de Aix-Marseille I. Áreas de atuação: Linguística Aplicada, Análise do discurso, Linguagem e Trabalho. São Paulo - SP - Brasil. E-mail: cecilinh@uol.com.br.
} 


\title{
Introdução
}

A música popular desempenha um papel importante na vida das pessoas, está sempre presente nos diversos momentos de convivência social. Seu gênero mais comum é a canção ${ }^{1}$, cujas letras costumam ser citadas, compartilhadas, lembradas em ocasiões especiais, enfim, as letras da música popular são exemplos de discursos com poder de persuasão, que agradam ao grande público de cada época. Também nos livros didáticos e nas aulas de língua materna as letras de músicas estão cada vez mais presentes, mas nem sempre a abordagem em relação a elas considera aquilo que é da ordem do discursivo. Nos Parâmetros Curriculares Nacionais de língua portuguesa, as letras da música popular são tomadas quase sempre como fonte de exemplos da variedade não culta da língua para o estudo da variação linguística (COSTA, 2003).

Em sua tese de doutorado junto ao programa de Linguística Aplicada e Estudos da Linguagem (LAEL), Costa (2001) defende que o discurso literomusical pode ser entendido como um discurso constituinte (MAINGUENEAU, 2001), discurso que dá sentido aos atos da coletividade, consistindo numa forma de vida articuladora da consciência coletiva a indicar modos de sentir, de pensar e de interpretar os fatos sócio-culturais.

Trata-se daquele discurso que estabelece um archéion, ou seja, determina um corpo de enunciadores consagrados e elabora uma memória para si e para a sociedade. Além disso, se constitui tematizando sua própria constituição, pretendendo ao mesmo tempo constituir-se para os outros (auto e heteroconstituição) e dizendo-se ligado a uma fonte legitimante (a Beleza, a Verdade, Deus, a musa inspiradora etc.):

\begin{abstract}
As canções são produtos de sujeitos concretos inseridos em um contexto densamente povoado de diálogos e de história, em que mesmo as canções mais simples são nós de uma intrincada configuração interdiscursiva, em que se influenciam mutuamente comunidades cancionistas (do passado e do presente, nacionais e estrangeiras), comunidades discursivas de outras instituições discursivas, discursos cotidianos, ideologias etc. (COSTA, 2001, p. 23).
\end{abstract}

No caso do samba, temos um gênero do discurso literomusical genuinamente brasileiro que se tornou um dos símbolos do país, desempenhando papel importante na constituição de uma identidade nacional (AZEVEDO, 2004, FENERICK, 2005; VIANNA, $1995)^{2}$.

\footnotetext{
${ }^{1}$ Embora tenhamos consciência de que o gênero canção é um gênero híbrido, de caráter intersemiótico, resultado da conjugação entre a materialidade verbal e a materialidade musical (ritmo, melodia), e que essas dimensões são de fato inseparáveis na conformação do gênero, trataremos aqui com maior ênfase da materialidade verbal. Tal opção é condizente com os pressupostos teóricos assumidos pois, conforme Maingueneau (2008b), a prática discursiva integra outros domínios semióticos além do verbal, tais como o pictórico e o musical, sendo portanto uma prática intersemiótica, em que "o sistema de restrições que funda a existência do discurso pode ser igualmente pertinente para esses outros domínios” (MAINGUENEAU, 2008b, p. 23). Tal sistema de restrições se define como uma semântica global, que permeia simultaneamente todos os planos da discursividade. Portanto, o mesmo conjunto de regras de formação (sistema de restrições) do material verbal vale para o material musical. Assim, o efeito de sentido de ironia no samba, por exemplo, não é resultado do material verbal ou do ritmo sincopado, tomados isoladamente, mas ambos são condizentes com o sistema de restrições semânticas que funda o samba. Tomar este ou aquele plano para análise é opção do analista, pois todos os planos a serem observados obedecerão às mesmas regras de uma determinada formação discursiva.

${ }^{2}$ Não é nossa intenção discutir, tal como o fazem os autores citados, o processo por meio do qual o samba se tornou símbolo nacional, processo que certamente passa por sua apropriação pelo projeto nacionalista de Getúlio Vargas. O mesmo se deu com o Carnaval carioca, que Vargas oficializou em 1933, antes mesmo de
} 
Postulamos, com Maingueneau (2008a), que o poder de persuasão de um discurso decorre não somente do que é dito, mas também da maneira de dizer, que é também uma maneira de ser, uma identidade; e que as diferentes maneiras de ser e de dizer correspondem a mundos éticos bem definidos que as legitimam. Interessa-nos compreender como as letras das canções populares refletem a realidade de cada época em termos de estereótipos, valores coletivos, socialmente construídos e atribuídos aos trabalhadores e ao trabalho. Para isso analisamos o ethos discursivo (MAINGUENEAU, 2008a) em letras de canções como "O bonde de São Januário”, de 1940, composta por Ataulfo Alves e Wilson Batista, e "Eu trabalhei”, de 1941, gravada por Orlando Silva exemplos de uma produção realizada sob a censura imposta pelo Estado Novo de Vargas -, "Cotidiano", de Chico Buarque de Holanda, do início dos anos 1970 - desta feita sob a censura do regime militar - e a recente "Trabalhador", de Seu Jorge, de 2007. Tal proposta insere-se em uma das vertentes do grupo Atelier Linguagem e Trabalho ${ }^{3}$, a de estudar os discursos produzidos por diferentes interlocutores nos quais o tema trabalho é relevante.

Após a análise do ethos nessas letras, perguntamo-nos sobre que época é essa, que mundo ético é esse que se constrói por meio de tal enunciação encarnada, e de que maneira o trabalho existe nesse mundo. Daí a importância de estudar os discursos produzidos por diferentes interlocutores nos quais o tema trabalho é relevante, e investigar como os sentidos de trabalho são construídos e ao mesmo tempo constroem os nossos discursos constituintes.

\section{Fundamentação teórica}

\subsection{Do ethos da Retórica ao ethos discursivo}

Na Retórica, a prova pelo ethos, parte da techné que o orador deve mobilizar, consiste em causar boa impressão mediante a forma com que se constrói o discurso, em dar uma imagem de si capaz de ganhar a confiança do auditório e alcançar a persuasão. Assim, o ethos está ligado à enunciação em si mesma, e não a um saber extradiscursivo sobre o locutor. Em outras palavras, o ethos é distinto dos atributos reais de um locutor de carne e ossos. Maingueneau (1997, 2005, 2008a) amplia essa noção em um quadro da Análise do Discurso para uma concepção mais "encarnada" do ethos, que recobre não apenas a dimensão verbal, mas também características físicas (corporalidade) e psíquicas (caráter) associadas ao fiador, sempre com base em estereótipos, representações sociais coletivas, que a enunciação pode reforçar ou transformar.

O modo como a Análise do Discurso de linha francesa trabalha a noção de ethos se distingue daquela da Retórica, sobretudo no que diz respeito à enunciação. A noção tal qual originalmente formulada na retórica aristotélica coloca o ethos como uma escolha do enunciador, à maneira "psicologizante" e "voluntarista" de um autor dono de seu dizer, que elaboraria a sua escolha em função dos efeitos que pretende produzir sobre seu auditório.

ser instaurado o Estado Novo. Desde então, o governo ofereceu subvenções ao concurso das escolas de samba, que a partir daquele momento deveriam apresentar temas ligados à grandeza da nação, de caráter didático, dando origem ao samba-enredo na forma como o conhecemos até hoje (PEREIRA, 2002).

${ }^{3}$ O grupo Atelier Linguagem e Trabalho (CNPq) originou-se, em 1997, no Programa de Estudos PósGraduados em Linguística Aplicada e Estudos da Linguagem, LAEL/PUC-SP. Reúne pesquisadores, doutorandos e mestrandos de diferentes universidades (PUC-SP, USP, UERJ, UNIRIO, UFF, UNISINOS, PUCRS e UTFPR). 
Do ponto de vista da AD, diz Maingueneau (1997, p. 45), “esses efeitos são impostos não pelo enunciador, mas pela formação discursiva”.

Dessa forma, a questão da adesão é também um reflexo do processo mais geral da adesão de sujeitos a uma certa posição discursiva (MAINGUENEAU, 2005, p. 69). A incorporação - maneira pela qual o leitor se apropria do ethos - ultrapassa a simples identificação a um fiador, implicando o acesso do leitor a um "mundo ético", que está impregnado no fiador, e ao qual ele dá acesso ao leitor por meio da enunciação. Assim, mesmo quando o fiador de um texto não é explicitado, quando há o apagamento do enunciador, o texto o mostra por meio de sua maneira de dizer, inserindo o leitor num mundo instaurado pela cena de enunciação, por uma cenografia, cena construída no e pelo discurso, também com a invocação de cenas validadas, já aceitas e instaladas na memória coletiva. A adesão aos discursos se dá então por um processo que envolve a cena de enunciação, da qual o ethos participa, e o conteúdo apresentado.

Se o ethos está crucialmente ligado ao ato de enunciação, diz Maingueneau (2005, p. 71), não se pode ignorar, entretanto, que o leitor constrói representações do enunciador antes mesmo que ele fale. A essas representações prévias, costuma-se chamar ethos prédiscursivo. Ainda que o leitor nada saiba sobre o enunciador, o simples fato de que um texto pertence a um gênero do discurso ou a um certo posicionamento ideológico, ou mesmo ao quadro de uma instituição, induz expectativas em termos de ethos.

É importante ressaltar que não se trata de considerar essa voz como um "sopro iniciador relacionado à intenção de uma consciência", mas do tom específico que constitui uma vocalidade que é uma dimensão, que faz parte da identidade de um posicionamento discursivo. Pode-se entender, portanto, essa "voz" como uma maneira de dizer que remete a uma maneira de ser.

Relacionando o conceito de ethos ao de cenografia, Maingueneau (2005) formulará um percurso de leitura dos sentidos nos textos:

O leitor reconstrói a cenografia de um discurso com o auxílio de indícios diversificados, cuja descoberta se apoia no conhecimento do gênero do discurso, na consideração dos níveis da língua, do ritmo etc., ou mesmo em conteúdos explícitos. Em uma cenografia [...] a figura do enunciador, o fiador, e a figura correlativa do co-enunciador são associadas a uma cronografia (um momento) e a uma topografia (um lugar) das quais supostamente o discurso surge. (MAINGUENEAU, 2005, p. 77)

Para explicar sua concepção de ethos, conceito que engloba aquilo que é anterior ao discurso também, na forma de um ethos pré-discursivo, o autor propõe o seguinte esquema: 
Figura 1 - 0 ethos discursivo

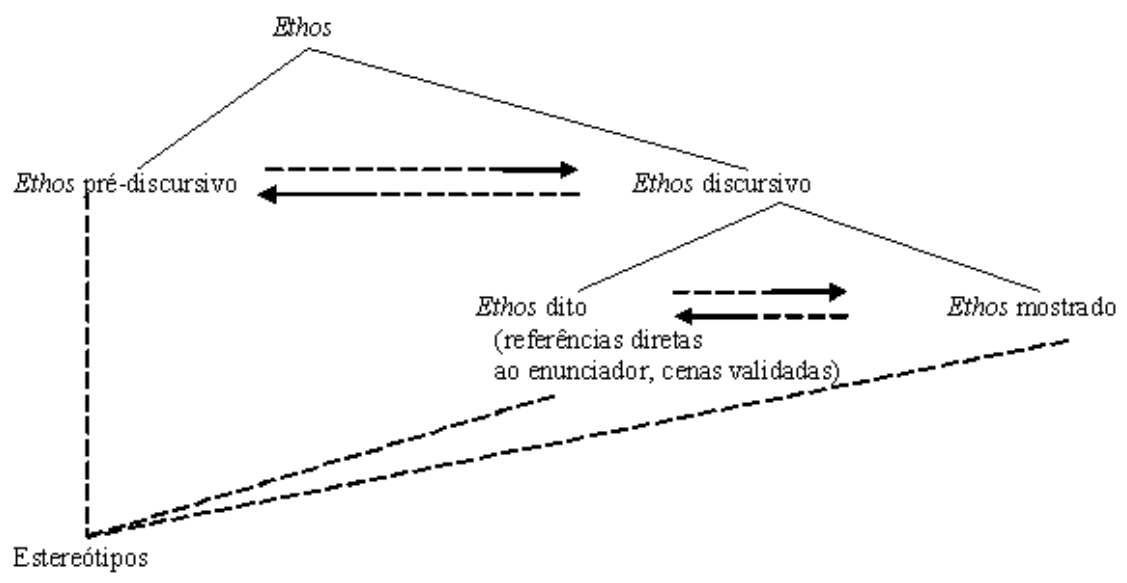

(Fonte: MAINGUENEAU, 2005, p. 83)

Maingueneau (2005) entende ethos como uma combinação do pré-discursivo com o discursivo, desse último discernindo o ethos dito - caracterizado pela referência direta ao enunciador ("eu sou um homem simples", p.e.) e/ou pela citação de cenas validadas em cada cultura -, do mostrado, aquele que decorre do "tom" do enunciado, daquilo que o enunciador diz não de si mesmo, mas daquilo que emana da forma de seu discurso, seu "tom", entendendo ainda que todas essas representações se tecem nos estereótipos próprios de cada cultura, em cada época.

\subsection{O discurso como prática discursiva}

Maingueneau (2008b; 1989) propõe aprofundar a articulação entre discurso e condições de produção, reformulando o termo prática discursiva, de Michel Foucault, para designar a reversibilidade essencial entre as duas faces do discurso, social e textual, quando se trata de apreender um discurso como inseparável das comunidades discursivas que o produzem e o difundem, sendo também, tais comunidades, ao mesmo tempo produzidas por esses discursos. Assim, o conceito integra conteúdos, modos de organização dos homens e redes específicas de circulação dos enunciados produzidos.

O conceito de comunidade discursiva designa os grupos que existem somente na e pela enunciação de textos que eles produzem e fazem circular. Há a imbricação de uma certa configuração textual e do modo de existência de um conjunto definido de indivíduos. Nessa perspectiva, dirá o autor que "todo estudo de enunciados que se interroga sobre seu modo de emergência, de circulação e de consumo, sem considerar o funcionamento dos grupos que os produzem e administram, só pode ser redutor” (MAINGUENEAU, 2008a, p. 143).

Por meio da noção de condições de produção se designa geralmente o "contexto social” que envolve um corpus, considerando desde sempre, em $\mathrm{AD}$, que a situação extraverbal nunca é apenas causa exterior dos enunciados, que não age do exterior como força mecânica, mas que age como constituinte necessário à estrutura semântica dos enunciados. Maingueneau (1989) aprofunda essa discussão, contestando a evidência enganadora das concepções que opõem ao interior do texto o exterior das condições de produção que o tornam possível, destacando a importância das comunidades que a enunciação de um discurso pressupõe. Fala da "comunidade daqueles que produzem, que 
fazem com que o discurso circule, que se reúnem em seu nome e nele se reconhecem" (MAINGUENEAU, 1989, p. 54).

Para a pergunta sobre em que condições um discurso é possível, dirá que não é suficiente lembrar a existência de um conflito social, de uma língua, de ritos e lugares institucionais de enunciação: “[...] é preciso lembrar que o próprio espaço de enunciação [...] supõe a presença de um grupo específico sociologicamente caracterizável, o qual não é um agrupamento fortuito de 'porta-vozes'” (MAINGUENEAU, 1989, p.54, grifo nosso). E, ainda:

\begin{abstract}
Não basta dizer que "entre” as informações brutas e os jornais existe o mundo da imprensa, "entre” os escritores e os textos literários, as instituições literárias, “entre” os cidadãos e os enunciados políticos, os meios políticos, e assim por diante. De fato, não dispõem inicialmente, das informações, dos escritores ou dos cidadãos; a seguir, das instituições mediadoras e, por fim, dos enunciados em circulação, mas tudo emerge ao mesmo tempo. A instituição "mediadora” não é secundária em relação a uma "realidade” que ela se contentaria em formular de acordo com certos códigos. [...] É preciso, de uma maneira ou de outra, considerar o modo de existência destes grupos que negam constantemente sua importância, ao se considerarem transparentes: fiéis zelosos, simples técnicos, representantes dos trabalhadores, consumidores etc., sempre se apresentam como portadores de mensagens (MAINGUENEAU, 1989, p. 54).
\end{abstract}

Tais "mensagens" das diversas comunidades discursivas são sempre compatíveis com os modos de existência das comunidades, e estão, portanto, sujeitas às coerções sociais e históricas. No entanto, como o diz Michel de Certeau (2005), mesmo naquelas práticas cotidianas supostamente entregues à passividade ou à disciplina, se pode encontrar alguma criatividade oculta, num emaranhado de astúcias sutis, por meio da qual os sujeitos encontram uma maneira própria de lidar com as práticas cotidianas impostas. No caso do samba, muitas vezes as práticas discursivas foram objeto de imposições e alvo de vigilância e censura por órgãos do governo. Dentre tais imposições, louvar o trabalho e a honestidade nas letras das canções, em oposição àquela ideia de malandragem que desde sempre caracterizara o samba, era uma das mais importantes.

\title{
20 ethos discursivo nas letras de alguns exemplares do samba
}

\subsection{Trabalho e malandragem na era Vargas}

O Estado Novo, que se estabeleceu por um golpe em 1937, deflagrou um processo de exaltação do nacionalismo, por meio do controle cultural e midiático. Em 1931, o presidente Vargas criara o Departamento Oficial de Propaganda, que depois, em 1939, seria transformado no Departamento de Imprensa e Propaganda (DIP), responsável pela censura à imprensa e pela propaganda ufanista do governo. Com seu crescente e promissor poder de influência, o rádio se tornou fundamental nesse processo. Em 1940, a Rádio Nacional passou a ser controlada pelo Estado e a apresentar programas musicais de conteúdo popular. Os compositores, além dos órgãos da imprensa em geral, são orientados a enfatizar, em sua atuação e em suas criações, ideias de incentivo e valorização do trabalho, evitando referências a comportamentos associados à malandragem, que era então uma marca estética do samba. A canção "Eu trabalhei”, de Roberto Roberti e Jorge Faraj (1941), gravada pelo cantor Orlando Silva, é um exemplo de produção desse período. Vejamos sua letra: 
Eu hoje tenho tudo, tudo que um homem quer

Tenho dinheiro, automóvel e uma mulher!

Mas pra chegar até o ponto em que cheguei

Eu trabalhei, trabalhei, trabalhei.

Eu hoje sou feliz

E posso aconselhar:

Quem faz o que eu já fiz

Só pode melhorar...

E quem diz que o trabalho não dá camisa a ninguém

Não tem razão, não tem, não tem.

(Fonte: www.letras.com.br)

“O bonde de São Januário", lançado um ano antes por Ataulfo Alves e Wilson Batista (1940), um compositor que foi várias vezes chamado ao DIP para explicações e vetos, também pertence a esse período:

Quem trabalha é que tem razão

Eu digo e não tenho medo de errar

O bonde São Januário

Leva mais um operário:

Sou eu que vou trabalhar.

Antigamente eu não tinha juízo

Mas resolvi garantir meu futuro

Vejam vocês:

Sou feliz, vivo muito bem

A boemia não dá camisa a ninguém

É, digo bem.

(Fonte: www.letras.com.br)

Nas duas letras identificamos, por meio dos dêiticos de primeira pessoa do singular, um enunciador arrependido da malandragem - "antigamente eu não tinha juízo”, "a boemia não dá camisa a ninguém”, “quem faz o que já fiz só pode melhorar” - que se dirige aos coenunciadores ${ }^{4}$ em tom de aconselhamento, notadamente por meio das modalidades epistêmicas (aquelas ligadas ao eixo do saber) em declarações assertivas sobre trabalho/não trabalho: "quem trabalha é que tem razão, eu digo e não tenho medo de errar”, “a boemia não dá camisa a ninguém, é, digo bem”, “e quem diz que o trabalho não dá camisa a ninguém não tem razão”.

Esse diálogo travado pelo enunciador-sambista com seus coenunciadores tem, entretanto, um interdiscurso claro, na medida em que seu discurso de louvor ao trabalho se faz pela oposição a um discurso da malandragem, da boemia, fundado já na memória discursiva do samba, e não pela simples apresentação das supostas vantagens que tem aquele que trabalha: “dinheiro, automóvel e uma mulher!”.

\footnotetext{
${ }^{4}$ Maingueneau ( 2001, p. 54) distingue, em francês, co-énonciateur e coénonciateurs: o primeiro, com hífen, vem substituir "destinatário"; o segundo, no plural e sem hífen, designa os dois parceiros do discurso. Em obediência às regras do português, manteremos sempre a grafia "coenunciador(es)", deixando ao contexto a tarefa de esclarecer seu sentido
} 
O ethos pré-discursivo do sambista é o do malandro, boêmio, muito mais afinado com uma paratopia ${ }^{5}$ de artista do que com a figura de homem do povo, trabalhador, operário. Assim, o ethos discursivo que emerge da letra dessas canções é o resultado desse pré-discursivo já transformado em estereótipo do sambista, combinado com o conteúdo das novas letras e um modo de enunciá-las que é típico do samba.

As artimanhas do sambista, aquela discreta criatividade, de que nos falava Certeau (2005), estão aí nesse interdiscurso, na prática discursiva que, colocando em relação o discurso de louvor ao trabalho e o discurso da boemia malandra do samba, faz reverberar os ecos da memória discursiva e instaura a contradição. Em lugar de todas as mulheres, uma mulher. Em lugar da distinção original do sambista boêmio, o rosto perdido na multidão: “o bonde de São Januário leva mais um operário, sou eu que vou trabalhar”.

O esforço repetido - "mas pra chegar até o ponto em que cheguei, eu trabalhei, trabalhei, trabalhei" - do ethos trabalhador precisa também repetir iguais vezes a negação do seu próprio passado pregresso: "quem diz que o trabalho não dá camisa a ninguém não tem razão, não tem, não tem”. E, lembremos, tudo isso dito no ritmo alegre, dançante, sincopado do samba, já assimilado em sua alegre malandragem na memória coletiva. Ao construir dessa forma um malandro arrependido como fiador do discurso, e o trabalho como caminho para uma felicidade simples, o samba reafirma a própria boemia e a fruição artística, a alegria própria do samba, como intervalo lúdico para o trabalhador comum.

Convém lembrar que, em matéria de ethos discursivo, nem sempre o ethos pretendido corresponde àquele que é produzido. "O professor que quer dar uma imagem de sério pode ser percebido como monótono, e aquele que quer dar a imagem de indivíduo aberto e simpático pode ser percebido como doutrinador ou 'demagogo'” (MAINGUENEAU, 2008a, p. 61).

\subsection{Trabalho e opressão no regime militar}

Durante o regime militar iniciado pelo golpe de 1964, todas as formas de censura já conhecidas na era Vargas foram intensificadas. Após a promulgação do Ato Institucional $\mathrm{n}^{\circ} 5$, todo e qualquer veículo de comunicação deveria ter sua pauta previamente aprovada e as redações ficaram sujeitas a inspeções por agentes do governo. A produção artística também ficou sujeita à censura prévia, e a divulgação de todo e qualquer material considerado não condizente com os ideais do regime era motivo de punição. Não eram censurados apenas os conteúdos diretamente relacionados à política, mas também aqueles considerados contrários à moral e aos bons costumes da época, incluída aí uma visão restrita de língua: o compositor Adoniran Barbosa teve letras censuradas por compor em dialeto caipira, com a promessa de que seriam liberadas se ele as adequasse à norma culta escrita.

Muitos compositores desse período encontraram meios de resistência e protesto por meio de sua música, por meio da manipulação competente do material linguístico e

\footnotetext{
5 “Paratopia é uma noção introduzida por Maingueneau (1995) para designar a relação paradoxal de inclusão/exclusão em um espaço social, uma difícil negociação entre o lugar e o não-lugar, que um locutor de um discurso constituinte ocupa para poder enunciar” (CHARAUDEAU; MAINGUENEAU, 2008, p. 368369). A noção foi originalmente usada para estudar o discurso literário, mas acreditamos ser perfeitamente possível aplicá-la ao discurso literomusical. Ao mesmo tempo em que o locutor-sambista se constrói como boêmio para ser criador, ele precisa se esforçar para superar seu impossível pertencimento ao lugar de boêmio para poder produzir, compor, realizar shows, gravar videoclipes, estar presente a eventos etc., ao mesmo tempo se esforçando, por meio da sua enunciação, para construir a imagem de boêmio que caracteriza essa própria enunciação.
} 
musical para produzir canções que passavam pela mediocridade intelectual dos censores e, divulgadas, agradavam ao grande público e se tornavam populares antes de serem finalmente censuradas. Chico Buarque era um desses compositores. A canção "Cotidiano", de 1971, embora não fale sobre trabalho diretamente, constrói por meio da enunciação o corpo - com todos os gestos e ações - e a voz oprimida pela rotina do trabalhador brasileiro comum. O ethos do trabalhador oprimido é que faz veicular o protesto à ditadura e à repressão, essa companheira multifacetada - onipresente, pontual, pretensamente protetora e amorosa, pavorosa - com a qual se tem de conviver calado:

Todo dia ela faz tudo sempre igual

Me sacode às seis horas da manhã

Me sorri um sorriso pontual

E me beija com a boca de hortelã

Todo dia ela diz que é pra eu me cuidar

E essas coisas que diz toda mulher

Diz que está me esperando pro jantar

E me beija com a boca de café

Todo dia eu só penso em poder parar

Meio dia eu só penso em dizer não

Depois penso na vida pra levar

E me calo com a boca de feijão

Seis da tarde como era de se esperar

Ela pega e me espera no portão

Diz que está muito louca pra beijar

E me beija com a boca de paixão

Toda noite ela diz pra eu não me afastar

Meia-noite ela jura eterno amor

E me aperta pra eu quase sufocar

E me morde com a boca de pavor

Todo dia ela faz tudo sempre igual

Me sacode às seis horas da manhã

Me sorri um sorriso pontual

E me beija com a boca de hortelã

(Fonte: BUARQUE, Chico)

Se perguntarmos sobre a corporalidade construída nesse texto, teremos o corpo do trabalhador, que levanta, toma café, sai para o trabalho, almoça sua marmita, volta para casa no final da tarde, dorme e se levanta do mesmo jeito no dia seguinte, para outro dia de trabalho. Por meio de uma sequência de cenas validadas, a letra recupera o estereótipo do trabalhador como massa de manobra. Embora a ideia de ação esteja atrelada a um personagem no feminino ("ela"), a mulher do trabalhador, que o acorda, o beija etc., quem relata as ações é um enunciador em primeira pessoa representado pelo pronome "me”, repetido à exaustão, produzindo efeito de sentido de total passividade. A passividade está também nas ações da mulher, do casal, mesmo aquelas que dizem respeito à relação amorosa mais íntima, todas repetitivas, pré-estabelecidas pelos estereótipos sociais, “como era de se esperar”. 
Passividade e rotina são a tônica na vida desse fiador, que se move num território de repetitividade. Todas as estrofes têm o mesmo esquema de composição, tanto na ordem do conteúdo temático quanto na ordem da estrutura sintática, "tudo sempre igual”. Com exceção da terceira estrofe, em primeira pessoa, que relata a ação na metade do dia, a hora do almoço, momento de intervalo e de possível quebra da rotina - "poder parar", "dizer não" - mas também aí o pronome reflexivo, em "me calo”, reforça a ideia de passividade e o retorno do esquema rotineiro.

A volta para casa, depois do trabalho, não apresenta nada novo: “como era de se esperar, ela pega e me espera no portão", depois beija, depois jura eterno amor. Se no dia de trabalho não há nada que possa significar fuga da rotina, tampouco na volta para casa isso ocorre. A última estrofe repete a primeira, o dia seguinte começa igual ao anterior. $\mathrm{O}$ efeito de sentido é de moto contínuo.

Num país sem liberdade, o cotidiano segue asfixiante, sufocante, nenhum encanto é possível, nenhuma criatividade. Esse é também o sentido de trabalho construído nesse percurso: nenhuma criatividade, nenhum prazer, somente um meio, penoso - "só penso em poder parar" - para obter a subsistência.

\subsection{Os sentidos de trabalho no samba depois da "redemocratização"}

Depois de décadas de ditadura e opressão, o povo brasileiro finalmente conheceu o sistema democrático de escolha de representantes políticos e uma economia de livre mercado. No período que se seguiu ao regime militar, e que ficou conhecido como "redemocratização", houve a convocação da Assembléia Nacional Constituinte, a promulgação da nova Constituição de 1988 e a eleição presidencial de 1989. Sem censura, a produção musical brasileira, como de resto toda a produção artística e intelectual, floresceu livremente na contemporaneidade, ainda que outras coerções, de outras naturezas (econômicas, de mercado, sócio-culturais etc.) se tenham feito presentes. Uma das características da produção contemporânea, num período que alguns autores chamam de pós-modernidade, é a tensão entre o regional e o global, a convivência entre gêneros originais e a experimentação de misturas inusitadas, não apenas na música, mas em todas as áreas do fazer artístico. O "samba rock" do compositor carioca Seu Jorge é um exemplo dessa produção. Tomamos aqui para análise a letra da canção “Trabalhador”, de 2007, que alcançou enorme popularidade depois de fazer parte da trilha sonora da novela "Duas Caras", da Globo. Vejamos o texto:

Está na luta, no corre-corre, no dia-a-dia

Marmita é fria mas se precisa ir trabalhar

Essa rotina em toda firma começa às sete da manhã

Patrão reclama e manda embora quem atrasar

Trabalhador

Trabalhador brasileiro

Dentista, frentista, polícia, bombeiro

Trabalhador brasileiro

Tem gari por aí que é formado engenheiro

Trabalhador brasileiro

Trabalhador

E sem dinheiro vai dar um jeito

Vai pro serviço

É compromisso, vai ter problema se ele faltar 
Salário é pouco, não dá pra nada

Desempregado também não dá

E desse jeito a vida segue sem melhorar

Trabalhador

Trabalhador brasileiro

Garçom, garçonete, jurista, pedreiro

Trabalhador brasileiro

Trabalha igual burro e não ganha dinheiro

Trabalhador brasileiro

Trabalhador

(Fonte: www.seujorge.com)

Nesta canção, diferentemente das demais aqui analisadas, não é o trabalhador quem fala, mas é dele que se fala. A voz do enunciador é a voz da denúncia, uma espécie de porta-voz de um protesto coletivo que não é o seu próprio, um “advogado” do trabalhador, a reclamar-lhe direitos e melhores condições, dentre elas, especialmente, uma remuneração mais justa.

O trabalhador é construído como grupo social amplo, formado por profissionais das mais diversas áreas, de ambos os sexos, e dos mais variados graus de instrução - "dentista, frentista, polícia, bombeiro”, "garçom, garçonete, jurista, pedreiro”-, todos eles sujeitos ao mesmo tipo de exploração e abandonados à falta de oportunidade.

A repetição exaustiva do item lexical "trabalhador" enfatiza também o cansaço: "trabalha igual burro" e a completa falta de perspectiva de melhora, de solução para a crise, numa situação que se encerra em si mesma: "salário é pouco, não dá pra nada/ desempregado também não dá/e desse jeito a vida segue sem melhorar”.

Uma das características mais marcantes do samba, o ritmo sincopado, continua presente. E a mistura com o rock - o próprio compositor denomina sua produção de samba rock $^{6}$-, mais alguns elementos do funk, dão à canção um balanço contemporâneo e um apelo dançante.

O efeito de sentido de trabalho que se constrói é o do trabalho como sacrifício, um mal necessário, que a todos iguala, sem escapatória, do funcionário assalariado da firma, o da marmita fria, ao profissional liberal (dentista), incluindo até mesmo o jurista, categoria que já desfrutou de elevado status social.

\section{Do trabalho que enobrece ao trabalho que oprime}

Embora tenhamos aqui uma análise apenas parcial de um conjunto bastante ínfimo de canções cuja temática é o trabalho, acreditamos que a análise permite verificar que, em diferentes momentos da vida nacional, mesmo naqueles em que o trabalho honesto deveria ser valorizado na música por força da censura e de outras formas de coerção pelos regimes ditatoriais, o ethos discursivo, essa voz que enuncia como fiadora dos discursos, nunca é a de alguém que tem poder. Também aquele que trabalha nunca tem condições de fazer fortuna, conseguindo no máximo o suficiente para continuar vivendo como assalariado.

O trabalho aparece, portanto, sempre com sentido de opressão, de obrigação, nunca de prazer. Poderia se questionar então, o porquê do tom sempre bem-humorado, algumas

\footnotetext{
${ }^{6}$ A denominação samba rock surgiu no final dos anos 60 com algumas composições de Jorge Ben e Jackson do Pandeiro, que tinham o samba por base e elementos do funk e do soul (PEREIRA, 2002).
} 
vezes irônico, mas nunca triste ou enfadonho desses discursos. E responderíamos, tranquilamente, que se trata de samba, música que é e sempre será associada à memória do malandro, à malandragem, um elemento essencial na paratopia do sambista.

\section{REFERÊNCIAS}

ALVES, A.; BATISTA, W. O bonde de São Januário. Intérprete: Cyro Monteiro. In: CYRO MONTEIRO. O bonde de São Januário/Morena brasileira: RCA Victor, 1940. 1 disco 78 rpm. Lado A.

AZEVEDO, R. J. D. Abençoado e danado do samba. Um estudo sobre as formas literárias populares: o discurso da pessoa, das hierarquias, do contexto, do senso comum e da folia. 883 f. Tese. (Doutorado em Teoria Literária) - Universidade de São Paulo, São Paulo, 2004.

BUARQUE, Chico. Cotidiano. Intérprete: Chico Buarque. In: CHICO BUARQUE. Construção: Philips, 1971. 1 LP. Faixa 2. Disponível em: <http://www.chicobuarque. com.br/construcao/mestre.asp?pg=cotidian_71.htm>. Acesso em: 15 nov. 2012.

CERTEAU, M. de A invenção do cotidiano: 1, artes de fazer (1990). Tradução Ephraim Ferreira Alves. 11. ed. Petrópolis, RJ: Vozes, 2005.

CHARAUDEAU, P.; MAINGUENEAU, D. Dicionário de análise do discurso. 2. ed. Coordenação Tradução Fabiana Komesu. São Paulo: Contexto, 2008.

COSTA, N. B. A produção do discurso litero-musical brasileiro. 410 f. Tese. (Doutorado em Linguística Aplicada e Estudos da Linguagem) - Pontifícia Universidade Católica de São Paulo, São Paulo, 2001.

COSTA, N. B. Canção popular e ensino da língua materna: o gênero canção nos Parâmetros Curriculares de língua portuguesa. Revista Linguagem em (Dis)curso, v. 4, n. 1, jul./dez. 2003.

FENERICK, J. A. Nem do morro, nem da cidade: as transformações do samba e a indústria cultural: 1920-1945. São Paulo: Annablume; FAPESP, 2005.

JORGE, S. Trabalhador. Intérprete: Seu Jorge. In: SEU JORGE. América Brasil: EMI, 2007. 1 CD. Faixa 2.

MAINGUENEAU, D. Analisando discursos constituintes. Revista do GELNE. v. 2, n. 2, 2001.

MAINGUENEAU, D. Ethos, cenografia, incorporação. In: AMOSSY, R. (Org.) Imagens de si no discurso: a construção do ethos. São Paulo: Contexto, 2005. p. 69-92.

MAINGUENEAU, D. Gênese dos discursos. Tradução Sirio Possenti. 1. rei. Curitiba, PR: Criar , 2008b. p. 7-48.

MAINGUENEAU, D. Novas tendências em análise do discurso. Tradução Freda Indursky. 3. ed. Campinas, SP: Pontes; Editora da Unicamp, 1989.

MAINGUENEAU, D. O contexto da obra literária: enunciação, escritor, sociedade. Tradução. Marina Appenzeller São Paulo: Martins Fontes. 1995.

MAINGUENEAU, D. Problemas de ethos. In: CENAS da enunciação. Organização de Sírio Possenti e Maria Cecília P. de Souza-e-Silva. São Paulo: Parábola Editorial, 2008a. p. 55-73. 
PEREIRA, S. L. Fragmentos da História Musical Brasileira. In: CONGRESSO LATINOAMERICANO DE INVESTIGADORES DE LA COMUNICACIÓN, 6., Santa Cruz de la Sierra, 2002. Disponível em: <http://www.eca.usp.br/associa/alaic/ material\%20congresso\%202002/2002\%20gt\%20Historia\%20de\%20la\%20Comunicacion \%20Juan\%20Gargurevich.htm>. Acesso em: 8 jan. 2011.

ROBERTI, R; FARAJ, J. Eu trabalhei. Intérprete: Orlando Silva. In: SILVA, Orlando. Eu trabalhei/A voz do povo, 1940. 1 Disco 78 rpm. Lado A.

VIANNA, H. O mistério do samba. Rio de Janeiro: Zahar; UFRJ, 1995.

Recebido em fevereiro de 2013.

Aprovado em abril de 2013. 